\title{
Association of Nodule Performance Traits with Shoot Performance Traits of Common bean Under Drought Stress
}

BERHANU AMSALU FENTA ${ }^{1,3}$, STEPHEN E. BEEBE ${ }^{2}$, IDUPULAPATI M. RAO ${ }^{2}$, and KARL J. KUNERT ${ }^{1}$

${ }^{1}$ Forestry and Agricultural Biotechnology Institute, Plant Science Department, University of Pretoria, Hillcrest, Pretoria 0002, South Africa.

${ }^{2}$ Centro Internacional de Agricultura Tropical (CIAT), A. A. 6713, Cali, Colombia

${ }^{3}$ Ethiopian Institute of Agricultural Research, Melkassa Agricultural Research Centre, P.O.Box, 436, Adama, Ethiopia

\section{Corresponding author:}

Address correspondence to Berhanu Fenta at Department Plant Science, Forestry and Agricultural Biotechnology Institute (FABI), University of Pretoria, Lynnwood Road, Hillcrest Pretoria, 0002, South Africa. E-mail: berhanu.fenta@up.ac.za

Running head: Common bean phenotypic markers

Date of submission: November, 2013

Number of figures: 2

Number of tables: 6 


\begin{abstract}
The effect of drought stress on the association of nodule performance traits with shoot performance traits was studied using six common bean lines with contrasting differences in their adaptation to drought and low phosphorus (P) availability in soil. Drought stress reduced leaf water potential and gas exchange characteristics $\left(\mathrm{CO}_{2}\right.$ assimilation, stomatal conductance) in all lines tested but two drought-tolerant lines, BAT 477 and BT_34-1,-1 were superior in their ability to adjust their leaf water status under drought. These two lines were also superior in root growth, rate of $\mathrm{CO}_{2}$ assimilation, vegetative biomass production, and nitrogen fixing ability under drought stress. A direct relation between symbiotic nitrogen fixation and nodule fresh weight with gas exchange traits as well as biomass production existed suggesting that relative growth of shoot vs. root depends on the provision of nitrogen by symbiotic nitrogen fixation and photosynthetic carbon assimilation. Overall, differences found in nodule, root and shoot performance traits indicated that the P-efficient bean line (BT_34-1-1) was superior than the other lines in terms of adaptation to drought. Results showed marked association of nodule performance traits with shoot performance traits under drought stress. We suggest that nodule characteristics and SNF ability should be included with above and below ground traits as phenotypic markers in germplasm evaluation and breeding programs that are aiming for improving drought tolerance in common bean.
\end{abstract}

Keywords: Phenotypic marker, Drought tolerance, Nodule performance, Biomass, Symbiotic nitrogen fixation 


\section{INTRODUCTION}

Drought causes a decline in $\mathrm{CO}_{2}$ assimilation, affects photochemical and biochemical reactions and restricts plant growth and dry matter accumulation. This ultimately results in a decrease of plant biomass and seed yield (Chaves et al. 2002). In common bean, stomatal conductance, which controls photosynthesis and transpiration of plants, is a major factor affecting plant adaptation to drought (Lawlor \& Cornic 2002). Regulation of stomatal opening and restriction of leaf expansion and growth of young leaves are among the key plant strategies for improved drought adaptation (White \& Singh 1991). Deep rooting ability under water-limited condition (White et al. 1990), heliotropic leaf movement for protection from photo-inhibition (Pastenes et al. 2005), early flowering or phenological adjustment (AcostaGallegos \& White 1994) as well as enhanced water and nitrogen use efficiency (Foster et al. 1995) are further adaptive or drought avoidance strategies in common bean. Bean cultivars with better performance under drought further maintain higher tissue water retention capacity and attain higher biomass (Costa Franca et al. 2000). Gebeyehu (2006) also reported a 29\% reduction of the harvest index for a susceptible bean line, whereas the harvest index for a tolerant line was unaffected.

Although various bean varieties have been previously tested for their response to drought, and results have been recently reviewed by Beebe et al. (2010), most of those studies focused primarily on above-ground (shoot) traits without particularly considering the contribution of nodules carrying out symbiotic nitrogen fixation (SNF) and supplying the plant with nitrogen required for plant growth (Dakora \& Keya 1997). Although common bean has a relatively low nitrogen fixation ability, it still fixes nitrogen of about $57 \mathrm{~kg}$ N/ha to 100 kg/ha (Herridge \& Danso 1995; Wani et al. 1995). Drought severely affects both SNF and plant biomass production (Serraj et al. 1999; Zahran 1999). In a previous study on soybean, 
higher plant biomass was directly related to higher SNF after drought treatment (Fenta et al. 2011). Decreases in plant biomass of up to $35 \%$ and SNF of up to $80 \%$ due to drought have further been found by Ramos et al. (1999). In the drought-tolerant bean cultivar EMGOPA201 , dry weight was unaffected by growth at $50 \%$ of field capacity, while both number and weight of nodules as well as SNF decreased under this condition. This indicates a higher sensitivity of SNF than biomass accumulation to drought in this cultivar (Ramos et al. 1999). Although SNF and nodule characteristics were evaluated before, their use as phenotypic markers for drought tolerance in beans and their association with above-ground traits under water deficiency have not been yet quantified widely. Inclusion of such nodule markers in bean evaluation programs for drought tolerance might, however, indispensable in the future for better exploitation of genetic diversity of beans supplementing currently mostly applied above-ground performance markers for selection.

In our study, we have, therefore, investigated several above-and below-ground drought performance traits in common bean. Traits were measured in different bean inbred lines provided by CIAT (see Table 1 for an overview) with varying degrees of drought tolerance, better nitrogen fixation and also more efficient phosphorous $(\mathrm{P})$ use. Studies were carried out in a temperature-controlled growth room with vermiculite as a growth medium. We particularly evaluated six lines that included two parents (DOR 364, BAT 477) and four recombinant inbred lines (RILs). Two bean lines were previously described as droughtsensitive (DOR 364 and BT_51-1-1), one drought-adapted (BT_6-1-1), one deep rooting with the ability of fixing more $\mathrm{N}$ under drought (BAT 477), and two with either efficient in P use (BT_34-1-1,) or inefficient in P use (BT-147-3). We were specifically interested in finding an association between below-ground characteristics (root and nodule biomass, SNF) and aboveground performance traits (shoot biomass, leaf area, gas exchange). Outcome of our study has provided evidence for a strong association between different performance parameters and the 
possible use of nodule performance traits as markers in drought tolerance screening of bean germplasm.

\section{MATHERIALS AND METHODS}

\section{Plant Material and Growth}

Plants of six common bean (Phaseolus vulgaris L.) lines with contrasting differences in adaptation to drought and low soil $\mathrm{P}$ availability (Table 1) were obtained from the International Center of Tropical Agriculture (CIAT) and were grown in a temperaturecontrolled growth room at the Forestry and Agricultural Biotechnology Institute (FABI), University of Pretoria $\left(-25^{0} 45^{\prime} 20.64^{\prime \prime} \mathrm{S}, 28^{0} 14^{\prime} 8.16^{\prime \prime} \mathrm{E}\right)$. The growth conditions consisted of a day/night temperature of $25^{\circ} \mathrm{C} / 17^{\circ} \mathrm{C}$ and $60 \%$ relative humidity, $13 \mathrm{~h}$ photoperiod at an average light intensity of photosynthetically active radiation of $600-800 \mu \mathrm{mol} \mathrm{m}^{-2} \mathrm{~s}^{-1}$. The photon flux density (PFD) was measured from 10 am to $3 \mathrm{pm}$ using a PAR 2 Meter with a SW 11L sensor (S.W \& W.S. Burrage, United Kingdom). Supplemental light, with a capacity of $300 \mu \mathrm{mol} \mathrm{m} \mathrm{m}^{-2} \mathrm{~s}^{-1}$, was supplied daily with metal-halide lamps from 4:00-7:00 $\mathrm{pm}$. The environmental conditions in the growth room were monitored regularly to ensure that adequate growth conditions were maintained.

One bean seed per pot was planted in $8 \mathrm{~cm}$ diameter pot and the emerging seedlings were transferred to a $15.5 \mathrm{~cm}$ round pot with a volume of $218.2 \mathrm{~cm}^{3}$ after two weeks or at the first trifoliate leaf (V1) stage. Seeds were inoculated before sowing with a Rhizobium leguminosarum biovar phaseoli powder $\left(0.5 \mathrm{~g}\right.$ per pot corresponding to $2.5 \times 10^{8}$ cells, Stimuplant CC., Pretoria, South Africa) to induce nodule formation. Plants were grown in vermiculite fine grade (Mandoval PLC, Potchefstroom, South Africa) to allow easier analysis 
Table 1 Characteristics and pedigree of common bean lines used in the study.

\begin{tabular}{llll}
\hline Line & Pedigree & Traits & Reference \\
\hline BAT 477 & $\begin{array}{l}(\text { G3834 x G4493) x } \\
(\text { G4792 x G5694) }\end{array}$ & $\begin{array}{l}\text { Deep rooting ability } \\
\text { Good N-fixer }\end{array}$ & $\begin{array}{l}\text { Sponchiado et al. 1989 } \\
\text { Hardarson et al. 1993 }\end{array}$ \\
& & $\begin{array}{l}\text { Fixing more N under } \\
\text { drought }\end{array}$ & $\begin{array}{l}\text { Peña-Cabriales \& } \\
\text { Castellanos 1993; } \\
\end{array}$ \\
& & & Castellanos et al. 1996 \\
DOR 364 & (BAT 1215 x (RAB 166 & Drought sensitive & Beebe et al. 1995; \\
& x DOR 125) & CIAT (1996) \\
BT 21138_34-1-1-M-M-M & RIL (DOR 364 x BAT & P-efficient & Drevon (unpublished) \\
(BT_34-1-1) & 477) & & Drevon (unpublished) \\
BT 21138_147-3-M-M-M & RIL (DOR 364 x BAT & P-inefficient & \\
(BT_147-3) & $477)$ & & CIAT 2007 \\
BT 21138_6-1-1-M-M-M & RIL (DOR 364 x BAT & Drought-adapted & \\
(BT_6-1-1) & $477)$ & & Blair et al. 2010 \\
BT 21138_51-1-1-M-M-M & RIL (DOR 364 x BAT & Drought-sensitive & \\
(BT_51-1-1) & $477)$ & & \\
\hline
\end{tabular}

${ }^{1}$ RIL: Recombinant inbred line developed by a single seed descent.

of root nodules. The treatments were placed in a completely randomized design (CRD) and during the experimental period pots were rearranged periodically.

\section{Plant Treatment}

Before the commencement of drought, plants were watered daily with $\mathrm{N}$-free distilled water for up to two weeks and then treated with a Hoagland's N-free nutrient solution every other day. Drought stress was initiated when plants were at the third trifoliate leaf stage (V3 stage) by completely withholding watering. For well-watered control plants, the maximum water holding capacity was maintained by daily watering throughout the experimental period. The maximum water holding capacity of vermiculite in this experiment was determined by watering equal amount of water to the well-watered pots and then allowing the vermiculite to 
absorb water for three hours until all micro- and macro-pores are filled and the remaining excess water was removed from the saucer on the bottom of the pots.

\section{Gas Exchange}

A portable Photosynthesis System (LI-COR, using LI-6400/LI-6400XT Version 6, LI-COR Bioscience, Lincoln, USA) was used to measure the net photosynthetic $\mathrm{CO}_{2}$ assimilation rate, stomatal conductance, transpiration rate, leaf temperature, internal $\mathrm{CO}_{2}$ concentration $(\mathrm{Ci})$ and $\mathrm{Ci} / \mathrm{Ca}$ (intercellular $\mathrm{CO}_{2}$ /ambient $\mathrm{CO}_{2}$ ) from the central leaflets of a fully matured $3^{\text {rd }}$ and the $4^{\text {th }}$ trifoliate leaf. This was carried out by clamping a leaf into a leaf cuvette. Levels of PFD and $\mathrm{CO}_{2}$ concentration inside the cuvette were maintained at $1000 \mu \mathrm{mol} \mathrm{m}^{-2} \mathrm{~s}^{-1}$ and 400 $\mu \mathrm{mol} \mathrm{mol}{ }^{1}$, respectively, while the air temperature was kept at $25^{\circ} \mathrm{C}$. The spot measurement was made on a $6 \mathrm{~cm}^{2}$ leaf area and measurements started after drought treatment until the assimilation rate approached almost zero (18 days of drought treatment). These measurements were conducted by sampling four individual plants from each line under each treatment (well-watered and drought). Instantaneous water use efficiency (IWUE) values were calculated as the ratios between $\mathrm{CO}_{2}$ assimilation rates and stomatal conductance values as described by (Soares-Cordeiro et al. 2009).

\section{Soil Water Content and Leaf Water Potential}

To determine the soil moisture content, vermiculite samples were taken every other day from all pots with a cylindrical core borer $(1.4 \mathrm{~cm}$ in diameter and $11 \mathrm{~cm}$ long). The fresh weight of the vermiculite sample was measured immediately with a balance of an accuracy of 0.001 g (Model B-502-S, METTLER TOLEDO, Greifensee, Switzerland). Samples were placed for drying into an oven (Type U 40, Mommert, Schwabach, Germany) at a temperature of $60^{\circ} \mathrm{C}$ 
for $48 \mathrm{hrs}$. The soil water content was calculated as percentage of the difference between the weight of the wet and oven-dried vermiculite samples.

The central leaflet used for gas exchange measurement was also used for measurement of the leaf water potential. Measurement was carried out with a pressure bomb (Model 3005, ICT International, Armidale, Australia) according to the method of Valenzuela-Vazquez et al. (1997). Since measurement was destructive to the leaf, measurements were made only at three time points during the drought treatment.

\section{Biomass and Leaf Area}

For quantifying the effect of drought stress on biomass accumulation, four individual plants from each bean line were harvested and the above-ground parts were separated into leaves with petioles, stems and pods. Below-ground parts (root and nodules) were separately harvested. Before oven-drying, the leaf area per plant was measured with a leaf area meter LI-COR 3100 (LI-COR Inc., USA). Dry weight was obtained from oven-dried samples after drying plant material at $60^{\circ} \mathrm{C}$ for 48 hrs. After drying, dry weight of each sample (leaf biomass, stem biomass, pod biomass, and root biomass) was measured for determination of total dry matter production.

\section{Symbiotic Nitrogen Fixation (SNF)}

SNF was measured with the acetylene reduction assay (ARA) method (Turner \& Gibson 1980; Hardy et al. 1973). All crown and lateral nodules of four individual plants for each line were harvested. After determination of fresh weight, nodules were placed in an airtight small flask of $43 \mathrm{ml}$ capacity and the ethylene production was determined after 10 min incubation with $4 \mathrm{ml}$ acetylene and injecting $1 \mathrm{ml}$ of gas from each flask into a gas chromatograph 
Varian 3900 (Varian Inc., USA). For calibration, a standard curve was made by injecting different levels of ethylene.

\section{Statistical Analysis}

All data were analysed with the JMP ${ }^{\circledR} 9$ (2011, SAS Institute Inc., Cary, NC, USA) statistical package. Analysis of variance was carried out for determining significant performance differences between the tested bean lines. Least Squares Means (LSmeans) student's t-test (P $=0.05)$ was applied for treatment comparison. Multivariate Pearson's correlation analysis was applied for determining the association (correlation) between measured traits. The pooled data of all lines and for the entire measurement period were analyzed for correlation.

\section{RESULTS}

\section{Soil Water Content and Leaf Water Potential}

The soil (vermiculite) water content was first determined on a mass basis by determining the percentage difference of the mass of wet and oven dry vermiculite. After 15 days of water depletion, the vermiculite water content for plants of lines BT_34-1-1 and BAT 477 was significantly $(\mathrm{p}<0.05)$ lower than for plants of the other lines (Figure 1A). Due to lower soil moisture content, the plant leaf water potential declined and plants of all lines had a significantly $(\mathrm{p}<0.05)$ lower water potential than well-watered control plants. DOR 364 and BT_147-3 had significantly $(\mathrm{p}<0.05)$ lower water potentials than all other lines under drought (Figure 1B). Plants of these two lines are very likely more water-stressed resulting in less water uptake when compared to the other lines (BAT 477 and BT_34-1-1) that adjusted their water status due to better water absorption of roots under stress. 

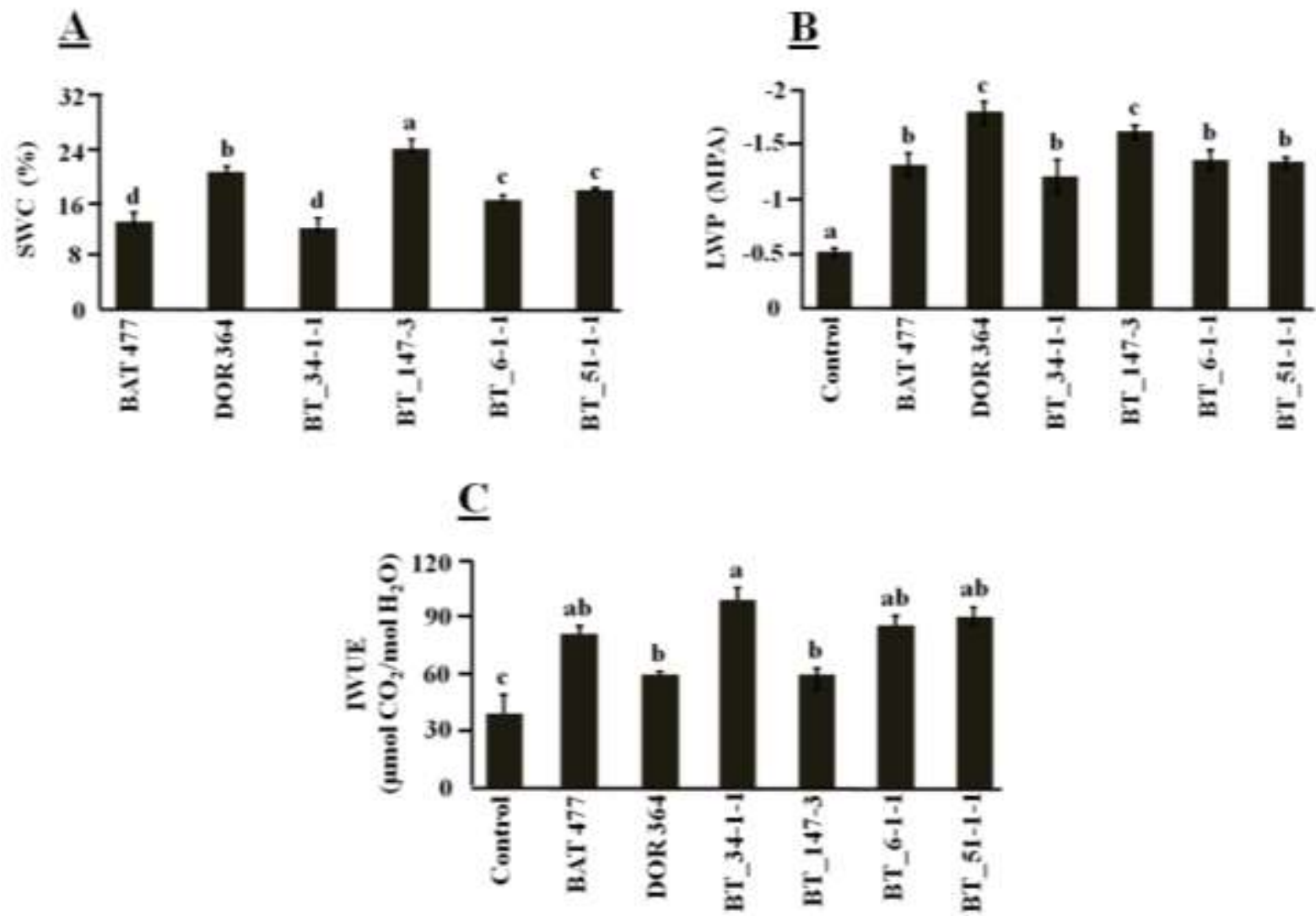

Figure 1 (A) Soil (vermiculite) water content (SWC), (B) leaf water potential (LWP), and (C) instantaneous water use efficiency (IWUE) after exposure of plants of six common bean lines for 15 days (SWC and IWEU) and 10 days (LWP) to drought or well-watered conditions. SWC value indicates the percentage difference of the mass of wet and oven dry vermiculite samples. Control (SWC and IWUE) represents the mean \pm SEM of 24 pooled plants (4 plants for each lines) grown under well-watered conditions. Each bar for various lines represents the mean \pm SE from of four individual plants. Different letters on bars denote significant difference $(\mathrm{P}<0.05)$.

\section{Gas Exchange}

In a further step, gas exchange traits were measured. Significant differences were found between lines when a one-way ANOVA was carried out covering the whole experimental period (Table 2). Lines significantly differed in $\mathrm{CO}_{2}$ assimilation and stomatal conductance under drought and also under well-watered conditions. Although at the onset of drought stress stomatal conductance and $\mathrm{CO}_{2}$ assimilation were not significantly different $(\mathrm{P}>0.05)$ 
Table 2 Analysis of variance for $\mathrm{CO}_{2}$ assimilation $\left(\mu \mathrm{mol} \mathrm{m} \mathrm{m}^{-2}\right)(\mathrm{A})$, stomatal conductance $\left(\mathrm{mmol} \mathrm{m} \mathrm{m}^{-2} \mathrm{~s}^{-1}\right)(\mathrm{G})$, leaf, stem and root dry weight (DW), nodule fresh weight $(\mathrm{FW})$ and symbiotic nitrogen fixation (SNF/g nodule fresh weight) of six common bean lines grown under well-watered or 18 days of drought exposure.

\begin{tabular}{|c|c|c|c|c|c|c|c|c|}
\hline \multirow{2}{*}{ Variation } & \multirow{2}{*}{ d.f. } & \multicolumn{6}{|c|}{ Means square } & \multirow[b]{2}{*}{ SNF } \\
\hline & & $\mathbf{A}$ & $\mathbf{G}$ & $\begin{array}{l}\text { Leaf } \\
\text { DW }\end{array}$ & $\begin{array}{l}\text { Stem } \\
\text { DW }\end{array}$ & $\begin{array}{l}\text { Root } \\
\text { DW }\end{array}$ & $\begin{array}{c}\text { Nodule } \\
\text { FW }\end{array}$ & \\
\hline \multicolumn{9}{|l|}{ Well-watered } \\
\hline Line & 5 & 17.761 & 210154 & 1.13 & 2.280 & 1.768 & 1.34 & 1.954 \\
\hline $\mathrm{P}$-value & & 0.027 & 0.012 & 0.003 & 0.008 & $<.0001$ & $<.0001$ & $<.0001$ \\
\hline Significance & & $*$ & $*$ & $* *$ & $* *$ & $* * *$ & $* * *$ & $* * *$ \\
\hline \multicolumn{9}{|l|}{ Drought } \\
\hline Line & 5 & 51.253 & 79162 & 1.032 & 1.10 & 5.024 & 0.755 & 1.425 \\
\hline P-value & & 0.037 & 0.043 & 0.004 & $<.0001$ & 0.002 & 0.0465 & 0.0067 \\
\hline Significance & & $*$ & $*$ & $* *$ & $* * *$ & $* *$ & $*$ & $* *$ \\
\hline Exp. Error & 84 & 20.64 & 43847.1 & 0.276 & 0.184 & 1.223 & 0.292 & 0.357 \\
\hline Total & 89 & & & & & & & \\
\hline
\end{tabular}

$*, * *$ and $* * *$ indicates significance at $\mathrm{P}<0.05, \mathrm{P}<0.01$ and $\mathrm{P}<0.001$, respectively.

between lines (Tables 3 and 4), after 7 days of drought BAT 477, a deep rooting and better Nfixing line under drought, had the highest stomatal conductance. Stomatal conductance was also significantly higher $(\mathrm{P}<0.05)$, than the other lines except for the P-efficient line BT_341-1 (Table 3). These two lines (BAT 477 and BT_34-1-1) had their stomata open allowing higher photosynthetic $\mathrm{CO}_{2}$ assimilation (Table 4). In contrast, lowest value of stomatal conductance after 7 days of drought was found in the drought-sensitive line BT 51-1-1 and the P-inefficient line BT_147-3. These two lines closed their stomata under drought resulting also in the lower values of $\mathrm{CO}_{2}$ assimilation (Table 4). Except for plants of the droughtadapted line BT 6-1-1, a similar trend of highest and lowest stomatal conductance and $\mathrm{CO}_{2}$ assimilation in the plants of the different lines tested was also found after 18 days of drought 
Table 3 Changes in stomatal conductance induced by drought conditions in six common bean lines at different time intervals. Data are the means \pm SEM of four different plants per line for each time point.

\begin{tabular}{lcccc}
\hline Lines & \multicolumn{4}{c}{ Stomatal conductance $\left(\mathbf{m m o l ~ \mathbf { ~ m } ^ { - 2 } \mathbf { ~ s } ^ { - \mathbf { 1 } } )}\right.$} \\
& $\mathbf{0 ~ d a y}$ & $\mathbf{7}$ days & $\mathbf{1 5}$ days & $\mathbf{1 8}$ days \\
& & & & \\
\hline BAT 477 & $662.7 \pm 47.4$ & $492.7 \pm 16.3 \mathrm{ab}$ & $49.1 \pm 7.1 \mathrm{a}$ & $24.2 \pm 1.4 \mathrm{ab}$ \\
DOR 364 & $578.3 \pm 81.2$ & $184.8 \pm 15.4 \mathrm{c}$ & $18.8 \pm 0.8 \mathrm{c}$ & $3.0 \pm 0.3 \mathrm{c}$ \\
BT_34-1-1 & $765.0 \pm 17.9$ & $576.9 \pm 25.3 \mathrm{a}$ & $31.8 \pm 1.2 \mathrm{ab}$ & $28.8 \pm 2.0 \mathrm{a}$ \\
BT_147-3 & $572.7 \pm 34.3$ & $167.6 \pm 13.1 \mathrm{c}$ & $21.2 \pm 1.8 \mathrm{c}$ & $3.6 \pm 0.5 \mathrm{c}$ \\
BT 6-1-1 & $651.3 \pm 85.5$ & $399.4 \pm 24.2 \mathrm{~b}$ & $34.9 \pm 3.4 \mathrm{ab}$ & $16.7 \pm 3.8 \mathrm{~b}$ \\
BT 51-1-1 & $585.0 \pm 15.5$ & $164.8 \pm 14.2 \mathrm{c}$ & $24.9 \pm 9.0 \mathrm{ab}$ & $2.5 \pm 0.3 \mathrm{c}$ \\
Significance & $\mathrm{ns}$ & $* *$ & $*$ & $* *$ \\
\hline
\end{tabular}

Significance level was determined using ANOVA $\left({ }^{* *} \mathrm{P}<0.001,{ }^{*} \mathrm{P}<0.05\right.$, and $\left.\mathrm{ns} \mathrm{P}>0.05\right)$ and difference between treatment means was determined using the LSmeans Student's t-test. Different letters within a column denote significant difference $(\mathrm{P}<0.05)$.

(Tables 3 and 4). Drought adapted line BT 6-1-1 also had high values of stomatal conductance and $\mathrm{CO}_{2}$ assimilation after drought that was also found for BAT 477 and BT_34-1-1.

When instantaneous water use efficiency (IWUE) was measured, all lines had significantly $(\mathrm{P}<0.05)$ higher IWUE under drought than grown under well-watered conditions (Figure 1C). However, both the drought-sensitive line DOR 364 as well as the P-inefficient line BT_147-3 had lower IWUE values under drought. In contrast, the P-efficient BT_34-1-1 had the highest IWUE which was significantly $(\mathrm{P}>0.05)$ higher than for lines DOR 364 and BT_147-3 (Figure 1C). 
Table 4 Changes in photosynthetic $\mathrm{CO}_{2}$ assimilation induced by drought conditions in six common bean lines at different time intervals. Data are the means \pm SEM of four different plants per line for each time point.

\begin{tabular}{|c|c|c|c|c|}
\hline \multirow{2}{*}{ Lines } & \multicolumn{4}{|c|}{$\mathrm{CO}_{2}$ assimilation $\left(\mu \mathrm{mol} \mathrm{m} \mathrm{m}^{-2} \mathrm{~s}^{-1}\right)$} \\
\hline & 0 day & 7 days & 15 days & 18 days \\
\hline BAT 477 & $14.16 \pm 0.17$ & $7.91 \pm 0.22 \mathrm{a}$ & $4.03 \pm 0.53 \mathrm{a}$ & $0.88 \pm 0.14 \mathrm{a}$ \\
\hline DOR 364 & $13.33 \pm 0.33$ & $5.64 \pm 0.39 b c$ & $1.11 \pm 0.3 b$ & $0.11 \pm 0.05 b$ \\
\hline BT_34-1-1 & $15.15 \pm 0.09$ & $7.59 \pm 0.24 \mathrm{a}$ & $3.15 \pm 0.4 \mathrm{a}$ & $0.87 \pm 0.05 a$ \\
\hline BT_147-3 & $13.43 \pm 0.42$ & $4.23 \pm 0.25 \mathrm{~cd}$ & $1.27 \pm 0.19 b$ & $0.16 \pm 0.09 b$ \\
\hline BT 6-1-1 & $14.42 \pm 0.53$ & $6.78 \pm 0.3 \mathrm{ab}$ & $2.98 \pm 0.13 \mathrm{ab}$ & $0.55 \pm 0.05 \mathrm{ab}$ \\
\hline BT 51-1-1 & $14.05 \pm 0.23$ & $3.97 \pm 0.28 \mathrm{~d}$ & $2.22 \pm 0.17 b$ & $0.10 \pm 0.11 b$ \\
\hline Significance & ns & $* *$ & $* *$ & * \\
\hline
\end{tabular}

Significance level was determined using ANOVA $\left({ }^{* *} \mathrm{P}<0.001,{ }^{*} \mathrm{P}<0.05\right.$, and $\left.\mathrm{ns} \mathrm{P}>0.05\right)$ and difference between treatment means was determined using the LSmeans Student's t-test. Different letters within a column denote significant differences $(\mathrm{P}<0.05)$.

\section{Plant Development and Biomass}

Tested lines significantly differed in leaf, stem and root dry weight under both drought and well-watered conditions (Table 2). P-efficient line BT_34-1-1 had the highest leaf, stem and root dry weight of all lines under both well-watered and drought conditions (Table 5). Most reduction in shoot biomass (leaf and stem) was found 18 days after drought treatment in both the drought-sensitive line DOR 364 and the P-inefficient line BT_147-3 (about 80\% reduction). Plants of the other four lines had only a 60-69\% reduction in shoot biomass (Table 5).

Drought stress increased the root biomass in all lines (Table 5). P-efficient line BT_341-1 had the highest root biomass and the P-inefficient line BT_147-3 as well as the droughtsensitive line DOR 364 had the lowest. A similar line response was found for the root/shoot 


\section{Table 5}

Dry weight (g) of plant parts, root / shoot (leaf and stem) dry weight ratio, and leaf area $\left(\mathrm{m}^{2}\right)$ of plants of six common bean lines after 18 days and leaf area after 15 days of exposure to well-watered conditions or exposure to drought. Data represent the mean \pm SEM of four independent plants per line.

\section{Well-watered}

\begin{tabular}{|c|c|c|c|c|c|c|c|}
\hline \multirow{2}{*}{ Lines } & \multicolumn{5}{|c|}{ Dry weight } & \multirow{2}{*}{ Root/shoot } & \multirow{2}{*}{ Leaf area } \\
\hline & Leaf & Stem & Pod & Root & Total & & \\
\hline BAT 477 & $3.24 \pm 0.53 \mathrm{a}$ & $1.72 \pm 0.33 \mathrm{ab}$ & $1.61 \pm 0.47$ & $1.67 \pm 0.22 \mathrm{a}$ & $6.57 \pm 1.39$ & $0.25 \pm 0.05$ & $13.47 \pm 0.74$ \\
\hline DOR 364 & $2.03 \pm 0.42 b$ & $1.29 \pm 0.3 \mathrm{ab}$ & $1.41 \pm 0.55$ & $1.05 \pm 0.17 b$ & $4.99 \pm 1.25$ & $0.21 \pm 0.05$ & $10.68 \pm 0.95$ \\
\hline BT_34-1-1 & $3.33 \pm 0.54 \mathrm{a}$ & $2.16 \pm 0.55 \mathrm{a}$ & $1.85 \pm 0.53$ & $1.77 \pm 0.24 \mathrm{a}$ & $7.34 \pm 1.51$ & $0.24 \pm 0.06$ & $12.12 \pm 0.88$ \\
\hline BT_147-3 & $1.96 \pm 0.25 b$ & $1.32 \pm 0.31 \mathrm{ab}$ & $2.44 \pm 0.67$ & $1.12 \pm 0.14 b$ & $5.71 \pm 1.26$ & $0.20 \pm 0.05$ & $10.78 \pm 0.81$ \\
\hline BT 6-1-1 & $2.84 \pm 0.67 \mathrm{ab}$ & $1.81 \pm 0.54 \mathrm{ab}$ & $2.17 \pm 0.73$ & $1.54 \pm 0.18 \mathrm{a}$ & $6.82 \pm 2.08$ & $0.23 \pm 0.06$ & $12.99 \pm 1.15$ \\
\hline BT 51-1-1 & $2.33 \pm 0.42 \mathrm{ab}$ & $1.12 \pm 0.34 b$ & $2.32 \pm 0.96$ & $0.98 \pm 0.17 b$ & $5.47 \pm 1.78$ & $0.18 \pm 0.04$ & $12.75 \pm 1.16$ \\
\hline Significance & $*$ & $* *$ & ns & $* *$ & ns & ns & ns \\
\hline
\end{tabular}


Significance level was determined using ANOVA $\left({ }^{* *} \mathrm{P}<0.001,{ }^{*} \mathrm{P}<0.05\right.$, and $\left.\mathrm{ns} \mathrm{P}>0.05\right)$ and difference between treatment means was determined using the LSmeans Student's t-test. Different letters within a column denote significant difference $(\mathrm{P}<0.05)$.

\section{Drought}

\begin{tabular}{|c|c|c|c|c|c|c|c|}
\hline \multirow{2}{*}{ Lines } & \multicolumn{5}{|c|}{ Dry weight } & \multirow{2}{*}{ Root/shoot } & \multirow{2}{*}{ Leaf area } \\
\hline & Leaf & Stem & Pod & Root & Total & & \\
\hline BAT 477 & $1.98 \pm 0.33 \mathrm{a}$ & $1.34 \pm 0.27 \mathrm{ab}$ & $1.48 \pm 0.36$ & $2.99 \pm 45 \mathrm{ab}$ & $4.80 \pm 1.2$ & $0.62 \pm 0.03 \mathrm{ab}$ & $9.90 \pm 0.21 \mathrm{a}$ \\
\hline DOR 364 & $1.62 \pm 0.35 \mathrm{~b}$ & $1.06 \pm 0.23 \mathrm{~b}$ & $1.08 \pm 0.29$ & $2.22 \pm 0.61 \mathrm{~b}$ & $3.77 \pm 1.35$ & $0.59 \pm 0.03 \mathrm{~b}$ & $7.48 \pm 0.43 \mathrm{c}$ \\
\hline BT_34-1-1 & $2.28 \pm 0.26 \mathrm{a}$ & $1.66 \pm 0.24 \mathrm{a}$ & $1.38 \pm 0.44$ & $3.74 \pm 0.65 \mathrm{a}$ & $5.32 \pm 1.25$ & $0.70 \pm 0.02 \mathrm{a}$ & $9.60 \pm 0.47 \mathrm{ab}$ \\
\hline BT_147-3 & $1.58 \pm 0.13 b$ & $0.97 \pm 0.11 b$ & $1.29 \pm 0.44$ & $2.22 \pm 0.46 \mathrm{~b}$ & $3.85 \pm 0.96$ & $0.57 \pm 0.03 b$ & $8.05 \pm 0.24 b c$ \\
\hline BT 6-1-1 & $1.75 \pm 0.24 \mathrm{ab}$ & $1.12 \pm 0.22 \mathrm{~b}$ & $1.59 \pm 0.26$ & $2.64 \pm 0.48 \mathrm{ab}$ & $4.46 \pm 1.13$ & $0.59 \pm 0.03 \mathrm{ab}$ & $9.36 \pm 0.21 \mathrm{ab}$ \\
\hline BT $51-1-1$ & $1.61 \pm 0.25 b$ & $0.96 \pm 0.18 b$ & $1.55 \pm 0.43$ & $2.62 \pm 0.66 \mathrm{ab}$ & $4.13 \pm 1.41$ & $0.63 \pm 0.02 \mathrm{ab}$ & $8.19 \pm 0.34 b c$ \\
\hline Significance & $* *$ & $* *$ & ns & * & $\mathrm{ns}$ & $*$ & $*$ \\
\hline
\end{tabular}

Significance level was determined using ANOVA $\left({ }^{* * *} \mathrm{P}<0.001,{ }^{*} \mathrm{P}<0.05\right.$, and ns $\left.\mathrm{P}>0.05\right)$ and difference between treatment means was determined using the

LSmeans Student's t-test. Different letters within a column denote significant difference $(\mathrm{P}<0.05$. 
ratio with the highest value with line BT_34-1-1 and the lowest with BT_147-3 (Table 5). Further, after 15 days of drought exposure, plants of the three lines BAT 477, BT_34-1-1 and BT 6-1-1 had significantly $(\mathrm{P}<0.05)$ more leaf area than the drought-sensitive line DOR 364 (Table 5).

\section{Nodule Performance}

In a further step, we measured nodule performance of different lines. Colour of nodules changed to green after 18 days drought treatment (data not shown). Since this indicates that nodules are no longer active in nitrogen fixation, SNF was measured at 7 and 10 days after drought exposure and data from the two measurements were pooled. Bean lines had significant differences for both nodule fresh weight and SNF under both growth conditions, well-watered and drought (Table 2). Plants of the more nitrogen fixing line BAT 477 and Pefficient line BT_34-1-1 had the highest nodule fresh weight under both well-watered and drought conditions while the drought-sensitive line DOR 364 as well as the drought-adapted line BT_6-1-1 (P < 0.05) showed the lower values (Figure 2A). Significant differences were also found for SNF among the lines under both growth conditions. The more nitrogen fixing line BAT 477 and P-efficient line BT_34-1-1 showed higher values of SNF under both conditions while the highest value of SNF was observed with BT_34-1-1compared with the other five lines under drought (Figure 2B).

Finally, we measured a possible association between nodule fresh weight and leaf and root dry weight as well as gas exchange parameters $\left(\mathrm{CO}_{2}\right.$ assimilation, stomatal conductance, intracellular $\mathrm{CO}_{2}$ concentration). A positive significant $(\mathrm{P}<0.05)$ association existed under well-watered conditions between nodule fresh weight with leaf and root dry weight as well as with gas exchange parameters $\left(\mathrm{CO}_{2}\right.$ assimilation, stomatal conductance, intracellular $\mathrm{CO}_{2}$ concentration) (Table 6). A positive significant $(\mathrm{P}<0.05)$ association was found under 
$\underline{\mathrm{A}}$

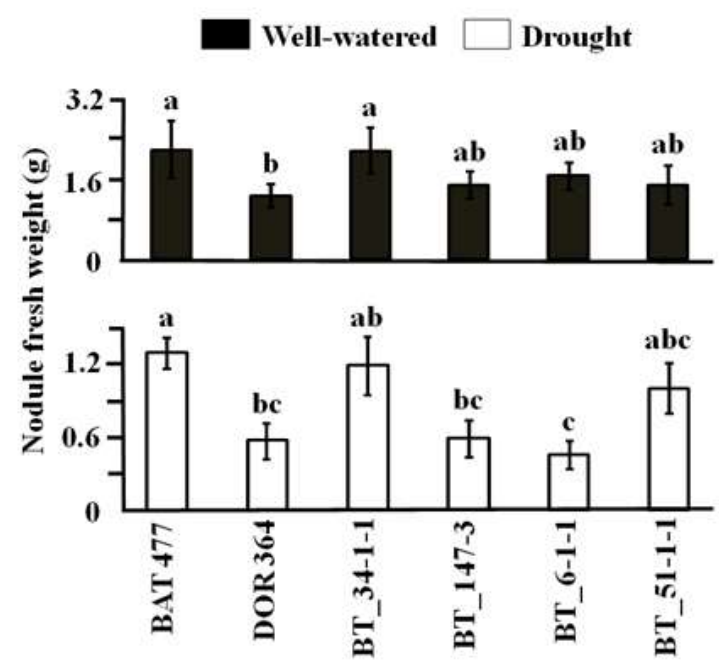

$\underline{\mathbf{B}}$

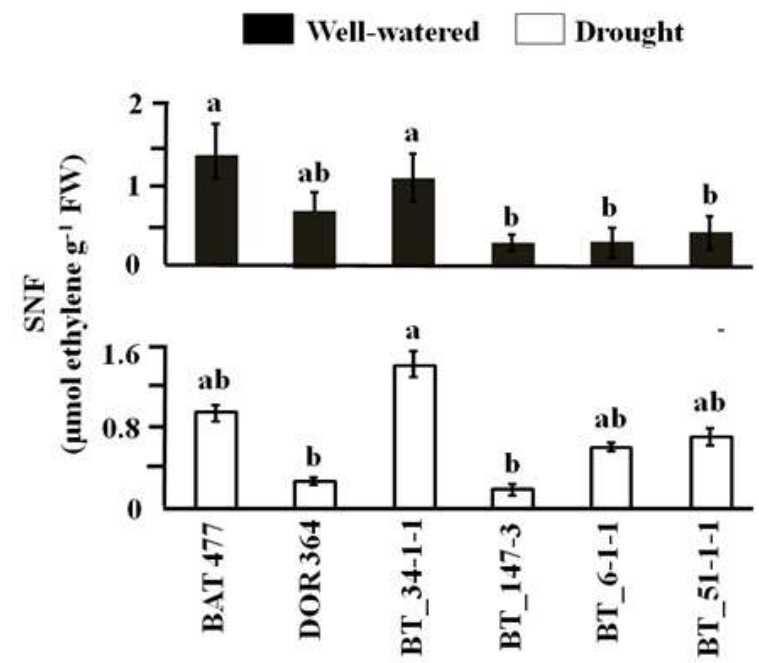

Figure 2 (A) Nodule fresh weight (A) and nodule SNF (ARA/g fresh weight /hour) (B) of plants of six different bean lines grown either under well-watered or drought conditions. Measurements were carried out 7 and 10 days after exposure of plants to either well-watered or drought conditions and individual data obtained from the two time points were pooled. Data represent the mean \pm SEM of 4 individual plants. Different letters on bar denote significant difference $(\mathrm{P}<0.05)$.

drought, identical to well-watered conditions, between nodule fresh weight and gas exchange parameters (Table 6). In contrast, a significant $(\mathrm{P}<0.05)$ negative association existed under drought between nodule fresh weight with total shoot and root dry weight (Table 6). When under well-watered conditions an association between SNF and various traits was investigated, a positive significant $(\mathrm{P}<0.05)$ association was found between SNF and root dry weight as well as gas exchange parameters $\left(\mathrm{CO}_{2}\right.$ assimilation, stomatal conductance, intra-cellular $\mathrm{CO}_{2}$ concentration) (Table 6). A positive significant $(\mathrm{P}<0.05)$ association further existed under drought, between SNF and gas exchange parameters but also between SNF and leaf area. 
Table 6 Association of growth and gas exchange characteristics with nodule fresh weight (FW) or SNF using Pearson's $\rho$ correlation analysis under drought and well-watered conditions. Data were pooled (days $0,7,10,15$ and 18) from all plants of all lines.

\begin{tabular}{|c|c|c|c|c|c|}
\hline \multirow{2}{*}{ Trait } & \multirow{2}{*}{ Trait } & \multicolumn{2}{|c|}{ Well-watered } & \multicolumn{2}{|c|}{ Drought } \\
\hline & & $\mathbf{r}$ & P-value & $\mathbf{r}$ & P-value \\
\hline \multirow{8}{*}{ Nodule FW } & Leaf area & 0.084 & 0.6749 & -0.150 & 0.4515 \\
\hline & Leaf DW & 0.366 & $0.0240 *$ & -0.112 & 0.8736 \\
\hline & Root DW & 0.502 & $0.0003 * * *$ & -0.567 & $0.0010 * *$ \\
\hline & Total shoot DW & 0.158 & 0.7502 & -0.624 & $0.0214^{*}$ \\
\hline & $\mathrm{CO}_{2}$ assimilation & 0.463 & $0.0041 * *$ & 0.873 & $0.0001 * * *$ \\
\hline & Stomatal conductance & 0.325 & $0.0018 * *$ & 0.885 & $<.0001 * * *$ \\
\hline & $\mathrm{Ci}$ & 0.244 & $0.0001 * * *$ & 0.338 & $<.0001 * * *$ \\
\hline & Leaf temperature & 0.075 & 0.4335 & -0.507 & 0.0670 \\
\hline \multirow{8}{*}{$\mathrm{SNF}$} & Leaf area & 0.046 & 0.2992 & 0.045 & $0.0378 *$ \\
\hline & Leaf DW & 0.266 & 0.0942 & 0.159 & 0.0874 \\
\hline & Root DW & 0.379 & $0.0006 * * *$ & -0.273 & 0.7182 \\
\hline & Total shoot DW & 0.016 & 0.1522 & 0.059 & 0.7316 \\
\hline & $\mathrm{CO}_{2}$ assimilation & 0.472 & $<.0001 * * *$ & 0.544 & $<.0001 * * *$ \\
\hline & Stomatal conductance & 0.545 & $<.0001 * * *$ & 0.638 & $<.0001 * * *$ \\
\hline & $\mathrm{Ci}$ & 0.36 & $0.0075^{* *}$ & 0.307 & $0.0161 *$ \\
\hline & Leaf temperature & 0.093 & 0.2322 & -0.231 & 0.5542 \\
\hline
\end{tabular}

$\mathrm{r}=$ Pearson's $\rho$ correlation coefficient; $\mathrm{CI}=$ Intracellular $\mathrm{CO}_{2}$ concentration, $\mathrm{DW}=$ dry weight; $\mathrm{SNF}=$ symbiotic nitrogen fixation (acetylene reduction activity/g nodule fresh weight/hour).

\section{DISCUSSTION}

In our study, all evaluated bean lines were affected by drought with gas exchange traits (stomatal conductance and $\mathrm{CO}_{2}$ assimilation) and $\mathrm{SNF}$ in nodules the most drought-sensitive traits. Our findings confirm previous reports of drought greatly decreasing leaf gas exchange 
activity and also N-fixation capacity in common bean and soybean (Castellanos et al., 1996; Fenta et al., 2011).

Our study allowed, however, selection of two bean lines performing best under drought. Both lines have, to our knowledge, not been evaluated yet in greater detail for any drought tolerance. BAT 477, with a deep rooting ability and fixing more $\mathrm{N}$ under drought, and BT_34-1-1, more efficient in P use under low P stress (J. Drevon, unpublished results), had highest stomatal conductance and photosynthetic $\mathrm{CO}_{2}$ assimilation after prolonged drought treatment. Plants of both lines also responded more rapidly to drought treatment with highest root and shoot (leaf and stem) dry weight as well as the highest root to shoot ratio (BT_34-11). Reduction of shoot dry weight, due to drought, is a common characteristic. However, enhanced root development under drought provides better water-uptake and allows the plants to keep their stomata relatively more open than the drought sensitive plants. Such an increase in the root to shoot dry weight ratio under drought has previously also been reported for soybean lines better performing under drought (Fenta et al. 2011; McCoy et al. 1990). Maintaining more open stomata, due to better water supply, also allows higher $\mathrm{CO}_{2}$ assimilation in beans (Yadav et al. 1997). Producing more root biomass as a response to drought, found for BT_34-1-1, improves plant performance and ultimately results in more shoot biomass and consequently better plant productivity under drought (DaCosta \& Huang 2006).

Drought decreased in all lines gas exchange, leaf water potential and biomass production. However, P efficient line BT_34-1-1 used available water more efficiently. Further, since line BT_34-1-1 had the highest IWUE, plants of this line very likely assimilate more $\mathrm{CO}_{2}$ per unit of stomatal conductance than plants of all other lines. Instantaneous water use efficiency (IWUE) is a suitable trait for selecting a superior bean line (Fenta et al. 2011). More effective water use, as a stress adaptive trait, helps in osmotic adjustment and 
sustaining stomatal conductance and eventually enhances $\mathrm{CO}_{2}$ assimilation (Blum 2011). In particular a deep root system, previously described as a characteristic for one parent, BAT 477, allows better water absorption and water use associated with higher productivity under drought (Pinheiro et al. 2005). A strong correlation also exists between improved $\mathrm{CO}_{2}$ assimilation, due to better water use, and ribulose-1,5-bisphosphate synthesis (Gimenez et al., 1992). Drought limits $\mathrm{CO}_{2}$ assimilation and ATP synthesis (Lawlor \& Cornic 2002). Less affected gas exchange, as found in BT_34-1-1, very likely results in better ATP supply to sustain cellular enzymatic activities.

A highly significant positive association under drought was found in our study between SNF as well as nodule fresh weight and gas exchange parameters but also between nodule fresh weight and shoot and root dry weight. Such positive association indicates that both gas exchange and SNF/noodle fresh weight contribute to above and below-ground plant performance. In particular the two best performing lines in our study, BAT 477 and BT_34-11, had highest SNF ability under both well-watered and drought conditions. SNF is a biological process demanding high energy and $\mathrm{CO}_{2}$ assimilation as a carbon source for nodule growth and function. When we also carried out a principal component analysis, SNF highly correlated with stomatal conductance and $\mathrm{CO}_{2}$ assimilation demonstrating the contribution of these two traits to SNF and vice versa (B. Fenta, unpublished results). Further, sucrose synthase activity, which is sensitive to drought, is also essential for nitrogen fixation to provide carbon supply for nodules (Gordon et al. 1999; Ramos et al. 1999). Droughttolerant bean lines have sucrose synthase activity less affected under drought than susceptible lines (Ladrera et al. 2007). Better stomatal conductance and $\mathrm{CO}_{2}$ assimilation under drought, as found in BAT 477 and BT_34-1-1, results in a better supply of carbon to the nodules allowing them to better perform under drought and enables them to effectively provide SNF products to the above-ground parts of the plant. 


\section{CONCLUSTION}

Results from our study have demonstrated the importance of growth and gas exchange parameters as well as nitrogen fixing ability to allow selecting a superior performing bean line for growth under drought. Gas exchange $\left(\mathrm{CO}_{2}\right.$ assimilation, stomatal conductance), growth (leaf area, shoot and root biomass) as well as nodule biomass and SNF determined in our study bean line performance variation. We could further establish an association between nodule performance and gas exchange traits. Measurement of performance traits allowed categorizing bean lines for performance under drought. Line BT_34-1-1 was the bestperforming line with BAT 477 the next best. BT 34-1-1, the most drought-tolerant line with highest SNF, has further the desirable trait of more P-efficient and important trait for growth in more acidic soils. Clay minerals, rich in acids soils, easily fix $\mathrm{P}$ rendering $\mathrm{P}$ unavailable for root uptake (Zheng 2010). By comparing different performance parameters we also found that nodule biomass was significantly associated with gas exchange and also total shoot biomass. Determination of biomass (shoot and nodules), although destructive, might be indispensable in future bean germplasm evaluation and breeding programs under non-N fertilization conditions.

\section{ACKNOWLEDGMENTS}

This work was funded by Tropical legume II (TL II) through International Centre of Tropical Agricultural (CIAT) Cali, Colombia and Pan Africa Bean Research Alliance (PABRA), Uganda providing a scholarship to Berhanu Fenta. 


\section{REFERENCES}

Acosta-Gallegos, J., and J. W. White. 1994. Phenological plasticity as an adaptation by common bean to rainfed environments. Crop Sci. 35:199-204.

Beebe, S. E., I. M. Rao, M. W. Blair, and J. A. Acosta-Gallegos. 2010. Phenotyping common beans for adaptation to drought. In Drought phenotyping: Theory and practice. Edited by P. Monneveux, and J. M. Ribaut. Generation Challenge Programme: Texcoco, Mexico, 311-334.

Beebe, S. E., I. Ochoa, P. Skroch, J. Nienhuis, and J. Tivang. 1995. Genetic diversity among common bean breeding lines developed for Central America. Crop Sci. 35:1178-1183.

Blair, M. W., C. H. Galeano, E. Tovar, M.C. Munoz Torres, A. Velasco Castrillo, S. Beebe, and I. Rao. 2010. Development of a Mesoamerican intra-genepool genetic map for quantitative trait loci detection in a drought tolerant $\mathrm{X}$ susceptible common bean (Phaseolus vulgaris L.) cross. Mol. Breed. 29:71-88.

Blum, A. 2011. Drought resistance - is it really a complex trait? Funct. Plant Biol. 38:753757.

Castellanos, J., J. J. Peña-Cabriales, and J. A. Acosta-Gallegos. 1996 . ${ }^{15} \mathrm{~N}$-determined dinitrogen fixation capacity of common bean (Phaseolus vulgaris) cultivars under water stress. J. Agric. Res. 126:327-333.

Chaves, M. M., J. S. Pereira, J. Maroco, M. L. Rodrigues, C. P. P. Ricardo, M. L. Osorio, I. Carvalho, T. Faria, and C. Pinheiro. 2002. How plants vope with water stress in the field? Photosynthesis and growth. Ann. Bot. 89:907-916.

CIAT. 1996. Bean program annual report, CIAT, Cali, Colombia.

CIAT. 2007. Bean program annual report, CIAT, Cali, Colombia. 
Costa Franca, M. G., A. T. Pham Thi, C. Pimentel, R. O. Pereyra Rossiello, Y. Zuily-Fodil, and D. Laffray. 2000. Differences in growth and water relations among Phaseolus vulgaris cultivars in response to induced drought stress. Environ. Exp. Bot. 43:227-237.

DaCosta, M., and B. Huang. 2006. Changes in carbon partitioning and accumulation patterns during drought and recovery for colonial bentgrass, creeping bentgrass, and velvet bentgrass. J. Am. Soc. Hortic. Sci. 131:484-490.

Dakora, F. D., and S. O. Keya. 1997. Contribution of legume nitrogen fixation to sustainable agriculture in Sub-Saharan Africa. Soil Biol. Biochem. 29:809-817.

Fenta, B. A., S. P. Driscoll, K. J. Kunert, and C. H. Foyer. 2011. Characterization of droughttolerance traits in nodulated soya beans: The importance of maintaining photosynthesis and shoot biomass under drought-induced limitations on nitrogen metabolism. J. Agric. Crop Sci. 198:92-103.

Foster, E. F., A. Pajarito, and J. Acosta-Gallegos. 1995. Moisture stress impact on N partitioning, $\mathrm{N}$ remobilization and $\mathrm{N}$-use efficiency in beans (Phaseolus vulgaris). $J$. Agric. Sci. 124:27-37.

Gebeyehu, S. 2006. Physiological response to drought stress of common bean (Phaseolus vulgaris L.) genotypes differing in drought resistance. Institut für Pflanzenernährung Justus-Liebig-Universität Giessen, Germany.

Gimenez, C., V. J. Mitchell, and D. W. Lawlor. 1992. Regulation of photosynthetic rate of two sunflower hybrids under water stress. Plant Physiol. 98:516-524.

Gordon, A. J., F. R. Minchin, C. L. James, and O. Komina. 1999. Sucrose synthase in legume nodules is essential for nitrogen fixation. Plant Physiol. 120:867-878.

Hardarson, G., F.A. Bliss, M. R. Cigales-Rivero, R. A. Henson, J. A. Kipe-Nolt, L. Longeri, A. Manrique, J. J. Pena-Cabriales, P. A. A. Preira, C.A. Sanabria, and S. M. Tsai. 1993. 
Genotypic variation in biological nitrogen fixation by common bean. Plant Soil 152:5970.

Hardy, R. W. F., R. C. Burns, and R. D. Holsten. 1973. Applications of the acetyleneethylene assay for measurement of nitrogen fixation. Soil Biol. Biochem. 5:47-81.

Herridge, D. F., and S. K. A. Danso. 1995. Enhancing crop legume $\mathrm{N}_{2}$ fixation through selection and breeding. Plant Soil 174:51-82.

Ladrera, R., D. Marino, E. Larrainzar, E. M. González, and C. Arrese-Igor. 2007. Reduced carbon availability to bacteroids and elevated ureides in nodules, but not in shoots, are involved in the nitrogen fixation response to early drought in soybean. Plant Physiol. 145:539-546.

Lawlor, D.W., and G. Cornic. 2002. Photosynthetic carbon assimilation and associated metabolism in relation to water deficits in higher plants. Plant Cell Environ. 25:275294.

McCoy, E. L., L. Boersma, and M. Ekasingh. 1990. Net carbon allocation in soybean seedlings as influenced by soil water stress at two soil temperatures. Bot. Gaz. 151:497505.

Pastenes, C., P. Pimentel, and J. Lillo. 2005. Leaf movements and photoinhibition in relation to water stress in field-grown beans. J. Exp. Bot. 56:425-433.

Peña-Cabriales, J., and J. Castellanos. 1993. Effect of water stress on $\mathrm{N}_{2}$ fixation and grain yield of Phaseolus vulgaris L. Plant Soil 152:151-155.

Pinheiro, H. A., F. M. Damatta, A. R. Chaves, M. E. Loureiro, and C. Ducatti. 2005. Drought tolerance is associated with rooting depth and stomatal control of water use in clones of Coffea canephora. Ann. Bot. 96:101-108. 
Ramos, M. L. G., A. J. Gordon, F. R. Minchin, J. I. Sprent, and R. Parsons. 1999. Effect of water stress on nodule physiology and biochemistry of a drought tolerant cultivar of common bean (Phaseolus vulgaris L.). Ann. Bot. 83:57-63.

Serraj, R., T. R. Sinclair, and L. C. Purcell. 1999. Symbiotic $\mathrm{N}_{2}$ fixation response to drought. J. Exp. Bot. 50:143-155.

Soares-Cordeiro, A.S., S. P. Driscoll, T. K. Pellny, E. Olmos, M. C. Arraba, and C. H. Foyer. 2009. Variations in the dorso-ventral organization of leaf structure and Kranz anatomy coordinate the control of photosynthesis and associated signalling at the whole leaf level in monocotyledonous species. Plant Cell Environ. 32:1833-1844.

Sponchiado, B. N., J. W. White, J. A. Castillo, and P. G. Jones. 1989. Root growth of four common bean cultivars in relation to drought tolerance in environments with contrasting soil types. Exp. Agr. 25:249-257.

Turner, L., and H. Gibson. 1980. Measurement of nitrogen fixation by indirect means. In Methods for Evaluating Biological Nitrogen Fixation. Edited by F.J. Bergersen. Wiley, Chichester, 111-138.

Valenzuela-Vazquez, M., A. Escobedo-Mendoza, J. L. Almanza-Sandoval , and A. RíosTorres. 1997. Pressure bomb. Final report: New Mexico state University

Wani, S.P., O. P. Rupela, and K. K. Lee. 1995. Sustainable agriculture in the semi-arid tropics through biological nitrogen fixation in grain legumes. Plant Soil 174:29-49.

White, J. W., J. A. Castillo, and J. Ehleringer. 1990. Associations between productivity, root growth and carbon isotope discrimination in (Phaseolus vulgaris L.) under water deficit. Funct. Plant Biol. 17:189-198.

White, J. W., and S. P. Singh. 1991. Breeding for adaption to drought. In: Common beans: research for crop improvement. Edited by A. Schoonhoven, and O. Voysest. C.A.B. International in association with Centro Internacional de Agricultura Tropical. 
Yadav, R., B. Courtois, N. Huang, and G. McLaren. 1997. Mapping genes controlling root morphology and root distribution in a doubled-haploid population of rice. Theor. Appl. Genet. 94:619-632.

Zahran, H. H. 1999. Rhizobium-legume symbiosis and nitrogen fixation under severe conditions and in an arid climate. Microbiol. Mol. Biol. Rev.63: 968-989.

Zheng, S. J. 2010. Crop production on acidic soils: overcoming aluminium toxicity and phosphorus deficiency. Ann. Bot. 106:183-184. 